\title{
Time-series observations of the structure and properties of brackish ice in the Gulf of Finland
}

\author{
T. Kawamura, ${ }^{1}$ K. Shirasama, ${ }^{2}$ N. Ishikawa, ${ }^{1}$ A. Lindfors, ${ }^{3}$ K. Rasmus, ${ }^{3}$ \\ M. A. Granskog, ${ }^{3}$ J. Ehn, ${ }^{3}$ M. Leppäranta, ${ }^{3}$ T. Martma, ${ }^{4}$ R. Vaikmä̈ ${ }^{4}$ \\ ${ }^{1}$ Institute of Low Temperature Science, Hokkaido University, Sapporo, Hokkaido 060-0819, Fapan \\ ${ }^{2}$ Sea Ice Research Laboratory, Institute of Low Temperature Science, Hokkaido University, \\ Minamigaoka, Mombetsu, Hokkaido 094-0013, Japan \\ ${ }^{3}$ Department of Geophysics, P.O. Box 4 ( Fabianinkatu 24 A), University of Helsinki, FIN-00014 Helsinki, Finland \\ ${ }^{4}$ Institute of Geology, Tallinn Technical University, 7 Estonia Blvd., EE-10143 Tallinn, Estonia
}

\begin{abstract}
The Baltic Sea is a semi-enclosed brackish water basin where sea ice occurs annually. The sea-ice study discussed here was conducted as a Finnish-Japanese cooperative research programme entitled "Ice Climatology of the Okhotsk and Baltic Seas" to investigate the structure and properties of the brackish ice in the Baltic Sea. Ice, snow and water samples were collected at Santala Bay, near the mouth of the Gulf of Finland, once a week from 20 January to 12 April 1999. The salinity and oxygen isotopic composition $\left(\delta^{18} \mathrm{O}\right)$ of the samples were measured. The ice samples were analyzed stratigraphically. The ice was composed of a granular upper layer, occupying approximately one-third of the entire ice thickness, and underlying columnar ice toward the bottom. The crystallographic structure and $\delta^{18} \mathrm{O}$ values reveal that the granular ice consisted of two layers with different origins, i.e. snow ice and superimposed ice. The fraction of snow relative to the total thickness was estimated. The limited data show a significant contribution of the snow cover to the sea-ice development. The salinity of the granular ice was higher than that of the columnar ice, implying that the mechanism of entrapment of brine may be different between the two ice types.
\end{abstract}

\section{INTRODUGTION}

The Baltic Sea ice is one of the key components in the North European climate system and in the physical and ecological environments in the area. The Baltic Sea is connected with the North Sea by a narrow and shallow strait and is therefore characterized as a semi-enclosed brackish water basin where sea ice occurs annually. The salinity of the Baltic is controlled by the balance between the inflow of saline water from the North Sea and of fresh water from riverine input and precipitation. The greater the distance from the North Sea, the lower the salinity. As a brackish water basin, the Baltic Sea provides excellent conditions to study specific physical phenomena, especially the role of salts in freezing processes.

Studies on ice structure have been conducted in both fast-ice and pack-ice areas in the Baltic Sea. Palosuo (1963) observed the snow depth and the thickness of different ice layers and took ice samples to determine the structure and salinity of ice at many stations on the Baltic Sea coast during three winters. Gow and others (1992) studied the planar/ non-planar structure of the ice/water interface for ice samples in the northernmost Baltic basin, the Bay of Bothnia. Ice crystallographic structures were observed along the Hanko Peninsula in the Gulf of Finland where the surface water salinity is $0.5-6.1 \mathrm{psu}$ (practical salinity units) (E. Palosuo and others, unpublished data). Studies in pack-ice areas have focused mainly on the deformation, dynamics and remote-sensing analyses, including ice thick- ness and structure in the Bay of Bothnia (e.g. Leppäranta, 1981, 1987; Askne and others, 1992; Gow and others, 1992).

A Finnish-Japanese cooperative research programme entitled "Ice Climatology of the Okhotsk and Baltic Seas" gave us an opportunity to study time-series observations of ice growth and structure at the Hanko Peninsula in the Gulf of Finland. The first series was collected in winter 1999. The aim was to obtain time-series data of snow and ice structure and to understand the development of snow and ice in the brackish water. One particular question was the formation of snow ice. This paper reports the results from this investigation of ice structure and properties, and discusses different growth processes.

\section{OBSERVATION AREA AND METHODS}

Ice observations were conducted once a week from 20 January at the onset of freeze-up until 12 April 1999. A total of 13 ice samples were collected during the period with an auger drill, a chain-saw and a handsaw on the fixed fast-ice area at Santala Bay, near the mouth of the Gulf of Finland (Fig. 1). These samples were analyzed for crystal structure, salinity and oxygen isotopes. An approximately $50 \mathrm{~g}$ snow sample from the near-surface layer and $50-100 \mathrm{~mL}$ water samples from the surface and ice/water interface were taken for salinity and oxygen isotope measurements.

The ice samples were put into plastic bags and kept at $-20^{\circ} \mathrm{C}$ in a storage chamber at Tvärminne Zoological 


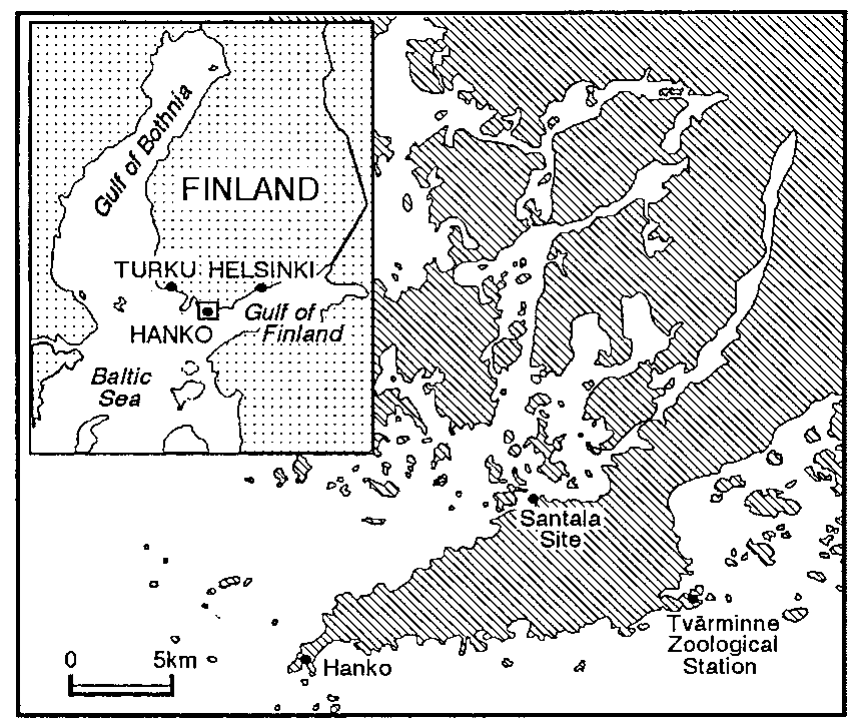

Fig. 1. Location of the Santala Bay sampling site.

Station, University of Helsinki, and analyzed in March and August in Tvärminne and at the State Technical Research Centre (VTT), Espoo, respectively. In the cold room, each sample was split lengthwise to obtain $5 \mathrm{~mm}$ thick vertical sections along the entire length. Horizontal thick sections were also produced at selected depths. These thick sections allowed us to examine bubble and brine layer distributions under scattered light. Then the sections were smoothed by planing to a thickness of $<1 \mathrm{~mm}$ and illuminated between crossed polarizers to identify individual grains and their structures. Analysis for $c$-axis orientation was conducted on grains on the horizontal thin sections with a universal stage. The entire length of the sample was cut at about $5 \mathrm{~cm}$ intervals as near as possible to structural boundaries. Then the pieces were melted in plastic bags for determination of the salinity with a conductivity meter (Radiometer, CDM 83 at Tvärminne, and Schott handylab LFl at Espoo). The standard sea-water formula was used to determine the salinity from the conductivity (Fofonoff and Millard, 1983; Fofonoff, 1985) to an accuracy of $0.1 \mathrm{psu}$. The oxygen isotope composition $\left(\delta^{18} \mathrm{O}\right)$ of the ice and snow samples was determined with a mass spectro-

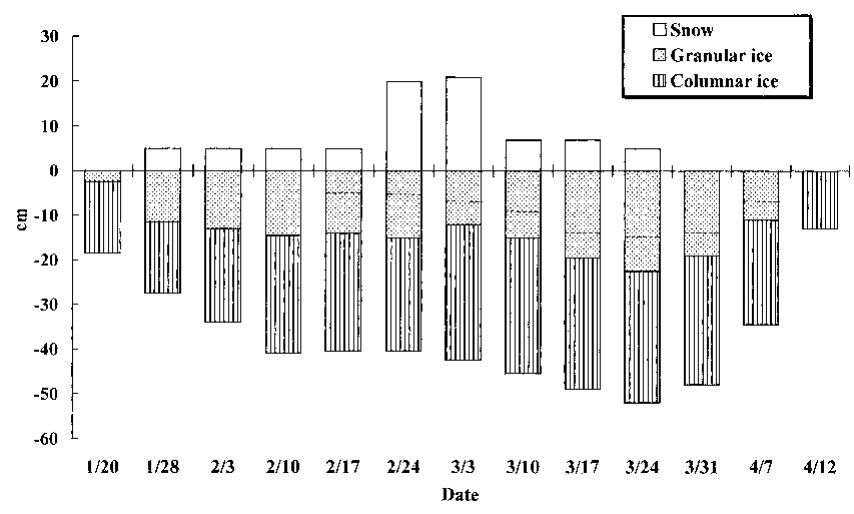

Fig. 2. Temporal changes of snow depth, and granular-ice and columnar-ice thicknesses during the sampling period. The snow/granular-ice interface is shown as the reference level. The dashed line in the granular ice indicates the boundary between superimposed ice and snow ice. Dates are month/day.
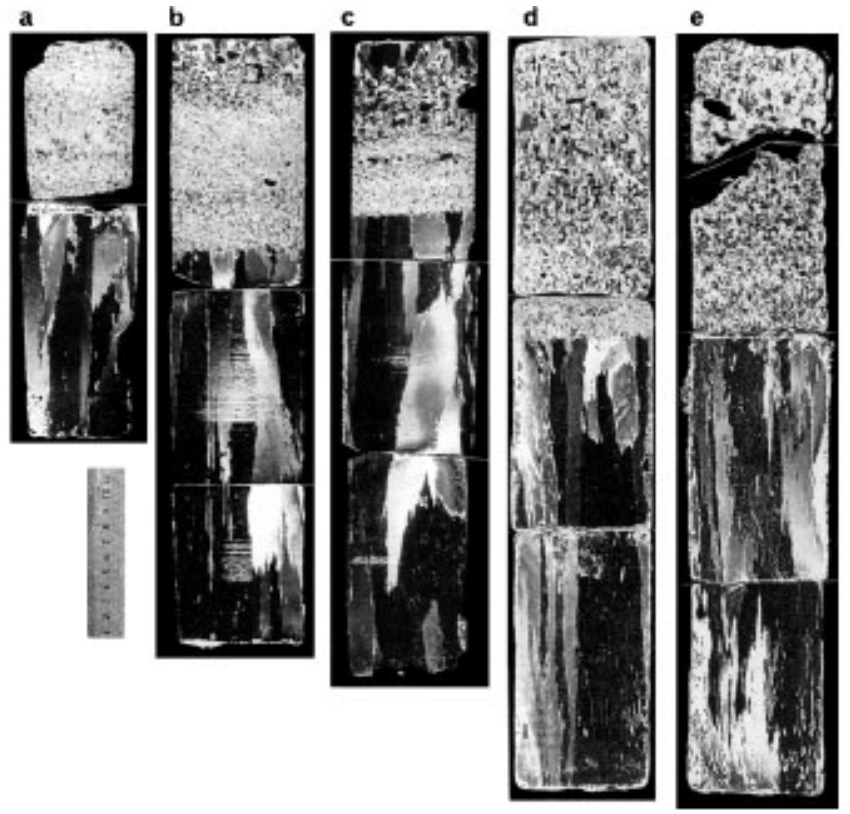

Fig. 3. Photographs of vertical thin sections of the ice samples at Santala Bay on (a) 28 January, (b) 17 February, (c) 3 March, (d) 17 March and (e) 31 March.

meter (Finnigan MAT Delta E, accuracy of $0.1 \%$ ) at the Institute of Geology, Tallinn Technical University, Estonia.

\section{RESULTS AND DISGUSSION}

Temporal changes in the thickness of the snow, granular ice and columnar ice are illustrated in Figure 2. The water-level elevation was not measured, but was estimated to be near the snow/ice interface by assuming snow and ice densities of 300 and $900 \mathrm{~kg} \mathrm{~m}^{-3}$, respectively. The ice thickness increased at a constant rate from $18 \mathrm{~cm}$ on 20 January to $41 \mathrm{~cm}$ on 10 February, and thereafter remained almost constant until 24 February. Then the thickness gradually increased again to a maximum of $53 \mathrm{~cm}$ on 24 March. Thereafter, the ice decayed abruptly to $12 \mathrm{~cm}$ on 12 April.

Photographs of vertical thin sections are shown in Figure 3. All samples contained ice of both granular and columnar structure. The former occupied the upper layer and accounted for approximately $30-40 \%$ of the entire ice thickness, while the latter involved the lower layer. The columnar ice had a characteristic sea-ice structure, i.e. a preferred horizontal $c$ axis, jagged grain boundaries and a substructure within the grains associated with brine layers.

Figure 4 shows profiles of salinity and oxygen isotopic composition of the snow, ice and water samples. The $\delta^{18} \mathrm{O}$ values of the snow cover were lower than $-10 \%$ and, in the minimum, exceeded $-20 \%$, being similar to those in Arctic regions (Dansgaard, 1964). The water salinity was 2-4 psu.

The above-mentioned crystal structure reflected a clear difference in the salinity and in the isotopic composition (Fig. 4). The salinity of the granular ice was higher than that of the columnar ice, implying that the mechanisms of entrapment of brine in the two ice types are quite different. In columnar ice, brine is mostly rejected during the ice growth, whereas in granular ice brackish water is incorporated into the pore spaces between the snow grains. The filling of pores with brine in permeable snow is likely to lead to higher salinities than brine incorporation in columnar 

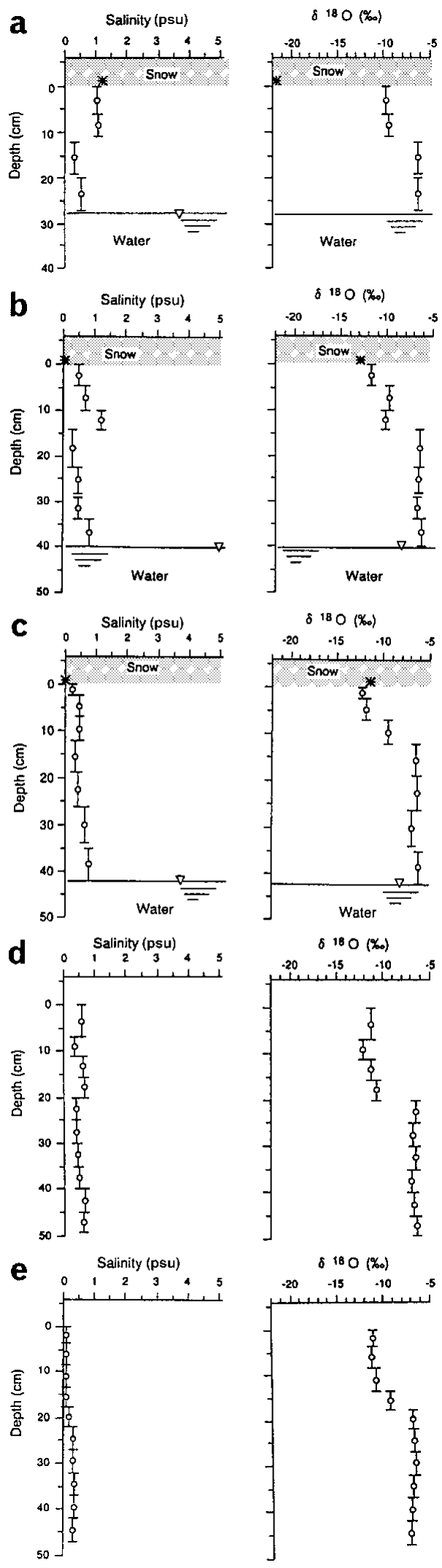

Fig. 4. Profiles of salinity and oxygen isotopic composition of snow, ice and water samples at Santala Bay on (a) 28 January, (b) 17 February, (c) 3 March, (d) 17 March and (e) 31 March.

ice. Granular ice had higher negative $\delta^{18} \mathrm{O}$ values than did the columnar ice, possibly because of the effect of snow cover which had extremely large negative values.

The $\delta^{18} \mathrm{O}$ data are used to determine the fraction of snow contributing to the granular layers and to the entire ice thickness (Jeffries and others, 1994). Their simplified version of the original model by Lange and others (1990) has the form

$$
\begin{gathered}
f_{\mathrm{s}}+f_{\mathrm{sw}}=1 \\
f_{\mathrm{s}} \delta_{\mathrm{s}}+f_{\mathrm{sw}} \delta_{\mathrm{sw}}=\delta,
\end{gathered}
$$

where $f_{\mathrm{s}}$ is the snow fraction, $f_{\mathrm{sw}}$ is the sea-water fraction of the granular ice, and $\delta$ is the mean $\delta^{18} \mathrm{O}$ value of the granularice layer for which the snow fraction is being determined.

For $\delta_{\mathrm{s}}$, we use measured $\delta^{18} \mathrm{O}$ values of the snow on each sampling day. The $\delta^{18} \mathrm{O}$ values of bottom columnar ice were about $2 \%$ higher than those of surface sea water of about $-9 \%$, which might be related to the isotopic fractionation that occurs during freezing. The fractionation factor is comparable to the values obtained previously (e.g. Craig and Hom, 1968; O'Neil, 1968). Therefore, taking into account the fractionation effect, we adopt the measured $\delta^{18} \mathrm{O}$ values of bottom ice at each sampling as $\delta_{\mathrm{sw}}$.

We tried to apply the equations to the early five samples with $\delta^{18} \mathrm{O}$ data. The $f_{\mathrm{s}}$ values calculated according to the model were $14-74 \%$ of the granular-ice thickness. The ratio of the granular-ice thickness to the entire thickness was estimated at $14-42 \%$. Multiplying $f_{\mathrm{s}}$ by this ratio, the snow fraction of the total ice thickness, $F_{\mathrm{m}}$, is calculated at 2$26 \%$. These $F_{\mathrm{m}}$ values are comparable to or larger than the values estimated for Antarctic sea ice (Lange and others, 1990; Eicken and others, 1994; Jeffries and others, 1994, 1997), where maximum snow contribution was $14-16 \%$ in summer ice in the Bellingshausen and Amundsen Seas (Jeffries and others, 1997). Therefore, in spite of the limited data, they indicate that a significant amount of snow contributes to the development of the sea ice in years such as 1999 when large snow accumulations occurred in this region.

The whole upper layer of granular ice was composed of very uniform and small grains in the early samples obtained during the period 20 January-3 February (Fig. 3a). However, after 17 February there was a structural boundary within the upper layer (Fig. 3b-e), with the ice layer above the boundary consisting of slightly larger and vertically elongated grains, while the underlying layer had smaller grains. The $\delta^{18} \mathrm{O}$ values for the granular ice with the smaller grains were between those for the water and the snow cover, whereas the granular ice containing the elongated grains had values similar to those in the snow cover (Fig. 4). This result suggests that the origins of the two granular-ice layers were different; the former was originated from a mixture of snow and sea water (i.e. snow ice), while the latter was formed from snowmelt water alone (i.e. superimposed ice) (Jeffries and others, 1994; Kawamura and others, 1997). The growth of superimposed ice became significant when the ice developed. The maximum superimposed-ice thickness of $28 \%$ of the total ice thickness occurred on 17 March.

The ice thickness increased steadily during the period 3-24 March (Fig. 2). Intensive investigation of the icestructure components shows that sea-ice growth during this period is not caused by columnar ice but by the upward growth of granular ice. This result also shows that the snow cover made a large contribution to sea-ice growth in this area. Moreover, comparing thin-section photographs (Fig. 3 ), we can conclude the upward ice growth is due primarily to superimposed-ice formation and secondarily to snow-ice formation.

Because superimposed ice is a result of melting and 


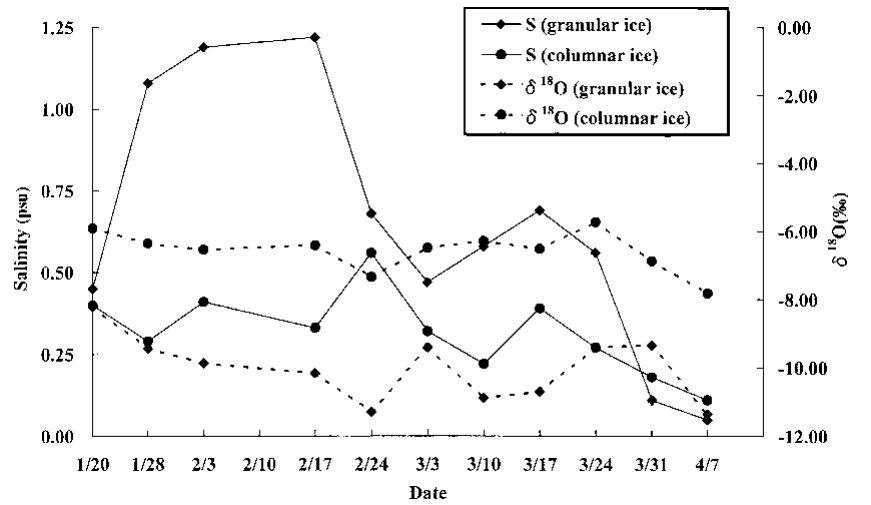

Fig. 5. Temporal changes of the salinity and oxygen isotopic composition in the granular-and columnar-ice layers at their boundary. Dates are month/day.

refreezing of snow cover, snowmelting is essential for its formation. Snowmelting could have been brought about by strong solar radiation, although the air temperature during this growth period was as low as $0^{\circ} \mathrm{C}$ at Tvärminne, about $10 \mathrm{~km}$ from Santala Bay. On the other hand, snow ice is formed when a snow layer soaked with sea water is refrozen. Therefore, a prerequisite for snow-ice formation is the depression of the snow/ice interface below the water level, i.e. a negative freeboard. We have observed negative freeboards on sampling days with thick snow cover (e.g. 24 February, 3 March), and would expect such conditions after heavy snowfalls.

A steady decrease in the total ice thickness was clearly observed after 24 March (Fig. 2). This occurs in both granular- and columnar-ice layers. The most plausible explanation in the case of granular ice is surface melting of the ice together with the snow cover as a result of a high air temperature above $0^{\circ} \mathrm{C}$ after $17 \mathrm{March}$, and, in the case of columnar ice, bottom melting due to an increasing water temperature after 26 March.

A closer inspection of the salinity and $\delta^{18} \mathrm{O}$ profiles in Figure 4 shows that there is a sharp change in salinity at the boundary between the granular- and columnar-ice layers. The salinity of granular ice at the boundary decreased sharply both from 17 February to 3 March and from 17 to 31 March, while underlying columnar ice kept salinity almost constant or gradually decreasing (Fig. 5). This result suggests that brine drainage might occur mainly in the granular-ice but not in the columnar-ice layer. On the other hand, the $\delta^{18} \mathrm{O}$ values of both granular and columnar ice did not change (Fig. 5), implying that the $\delta^{18} \mathrm{O}$ values might be affected only by the solid part of the ice but not by brine.

\section{CONGLUSIONS}

Ice samples were collected once a week during the period January-April 1999 at Santala Bay near the mouth of the Gulf of Finland. Temporal variability in the ice structure as well as in the salinity and oxygen isotopic composition was examined.

The ice-structural analysis reveals that granular ice composed approximately one-third of the whole length and that it was made up of both snow ice and superimposed ice which grew upward. This result clearly shows a significant contribution from snow cover to sea-ice growth in this area.
The salinity of the granular ice was higher than that of the columnar ice. The salinity of granular ice at the granular-/ columnar-ice boundary decreased sharply. These results imply that the mechanism of entrapment and retention of brine pockets may differ between the two ice types.

We propose further studies for the ice structure and properties in the brackish water as follows: Santala Bay provides excellent conditions to study temporal changes of ice properties in brackish water. Observations of ice should be carried out together with meteorological and oceanographic observations, preferably from the beginning of the ice season. Snow cover should be sampled more systematically.

\section{AGKNOWLEDGEMENTS}

We wish to thank the personnel of the Tvärminne Zoological Station for their kind permission to use their facilities. Thanks are extended to E. Uematsu for drawing. This work is a part of the project "Ice Climatology of the Okhotsk and Baltic Seas", financed by the Japanese-Finnish Bilateral Programs with the Japan Society for the Promotion of Science and the Academy of Finland, and also the Finnish Ministry of Trade and Industry and the Japanese Ministry of Education, Science, Sports and Culture (Monbusho) through grant-in-aid for scientific research.

\section{REFERENGES}

Askne, J., M. Leppäranta and T. Thompson. 1992. Bothnian experiment in preparation for ERS-1, 1988 (BEPERS-88): an overview. Int. 7. Remote Sensing, 13(13), 2377-2398.

Craig, H. and B. Hom. 1968. Relationships of deuterium, oxygen 18, and chlorinity in the formation of sea ice. American Geophysical Union Transactions, 49 (1), 216-217.

Dansgaard, W. 1964. Stable isotopes in precipitation. Tellus, 16(4), 436-468.

Eicken, H., M. A. Lange, H.-W. Hubberten and P. Wadhams. 1994. Characteristics and distribution patterns of snow and meteoric ice in the Weddell Sea and their contribution to the mass balance of sea ice. Annales Geophysicae, 12(1), 80-93.

Fofonoff, N. P. 1985. Physical properties of seawater: a new salinity scale and equation of state for seawater. F. Geophys. Res., $\mathbf{9 0}$ (C2), 3332-3342.

Fofonoff, N. P. and R. C. Millard, Jr. 1983. Algorithms for computation of fundamental properties of seawater. UNESCO Tech. Pap. Mar. Sci. 44.

Gow, A. J., W. F. Weeks, P. Kosloff and S. Carsey. 1992. Petrographic and salinity characteristics of brackish water ice in the Bay of Bothnia. CRREL Rep. 92-13.

Jeffries, M. O., R. A. Shaw, K. Morris, A. L. Veazey and H. R. Krouse. 1994. Crystal structure, stable isotopes $\left(\delta^{18} \mathrm{O}\right)$, and development of sea ice in the Ross, Amundsen, and Bellingshausen seas, Antarctica. 7. Geophys. Res., $99(\mathrm{Cl})$, 985-995.

Jeffries, M. O., A. P. Worby, K. Morris and W. F. Weeks. 1997. Seasonal variations in the properties and structural composition of sea ice and snow cover in the Bellingshausen and Amundsen Seas, Antarctica. 7 . Glaciol., 43(143), 138-151.

Kawamura, T., K. I. Ohshima, T. Takizawa and S. Ushio. 1997. Physical, structural and isotopic characteristics and growth processes of fast sea ice in Lützow-Holm Bay, Antarctica. F. Geophys. Res., 102(C2), 3345-3355.

Lange, M. A., P. Schlosser, S. F. Ackley, P. Wadhams and G. S. Dieckmann. 1990. ${ }^{18} \mathrm{O}$ concentrations in sea ice of the Weddell Sea, Antarctica. $f$. Glaciol., 36(124), 315-323.

Leppäranta, M. 1981. On the structure and mechanics of pack ice in the Bothnian Bay. Finn. Mar. Res. 248, 3-86.

Leppäranta, M. 1987. Field experiment SEA ICE-85, in mid-winter in the Bay of Bothnia. Meri, 15, 15-33.

O'Neil, J. R. 1968. Hydrogen and oxygen isotope fractionation between ice and water. 7. Phys. Chem., 72(10), 3683-3684.

Palosuo, E. 1963. The Gulf of Bothnia in winter. II. Freezing and ice forms. Merentutkismuslaitoksen Julkaisu/Havsforskningsinst. Skr. 209, 42-64. 